\title{
Training Students' Innovation Capacity Based on Building Practical Teaching System
}

\author{
DU Yun ${ }^{1, a}$, LIANG Guozhuang ${ }^{1, b}$, ZHANG Suying $^{1, c}$ and LIANG Yongchun ${ }^{1,2, d}$ \\ ${ }^{1}$ School of Electric Engineering, Hebei University of Science and Technology, Shijiazhuang 050018, \\ China \\ ${ }^{2}$ The corresponding author \\ ayunny7503@163.com, '263855298@qq.com, '923252999@qq.com, d379269095@qq.com
}

Keywords: Practical teaching system, Close docking, Innovation capacity, Entrepreneurial ability

\begin{abstract}
In order to achieve close docking between graduates and enterprises, three-dimensional, multi-level practical teaching system was built for application-oriented talents training of electric and information specialty in this paper. Four levels including 'time throughout', 'deepness hierarchies', 'form diversity' and 'contents comprehensiveness' are discussed. For strengthening the students' practical engineering ability, innovation and entrepreneurial capacity the four levels which have their own characteristics and a complex nexus of cross-cutting could lay the foundation for the training of electrical and information professionals of the 21st century.
\end{abstract}

\section{Introduction}

The United States has made statistics in 1950s, the proportion of develop talents, front-line engineering technicians and skilled workers goes from 2:2:6 to 2:6:2 until 1990s.The statistical results reflect the increasing demand of undergraduate talents with applied ability and creative ability because of economic development [1], higher requirement of the practice quality level of college graduates, so universities are required to adjust the talent training models. Electrical and information disciplines as wide caliber professional are very practical professional which the students must have strong practical ability in addition to solid theoretical foundation. According to the guiding ideology of strengthening basic, diluting professional knowledge, broadening knowledge scope and focusing on engineering practice, to ensure the teaching quality and solve the problem which graduates cannot achieve close docking with enterprises, practical teaching stage must be explored and practiced.

\section{Structure of Multi-level Three-dimensional Practical Teaching System}

Having made a lot of research and practice for years, our school built a multi-level three-dimensional practical teaching system which is shown in Fig.1. The system includes four levels which are 'time throughout', 'deepness hierarchies', 'form diversity' and 'contents comprehensiveness'. During teaching the different branches of the practical aspects, the system made targeted building in aspects of teaching software and hardware, teachers, teaching methods and mode according to the requirements of students' basic skills of each level. Each specific practical program is not only specific practical training mission in the chain, but also is the connecting link in the system [2]. 


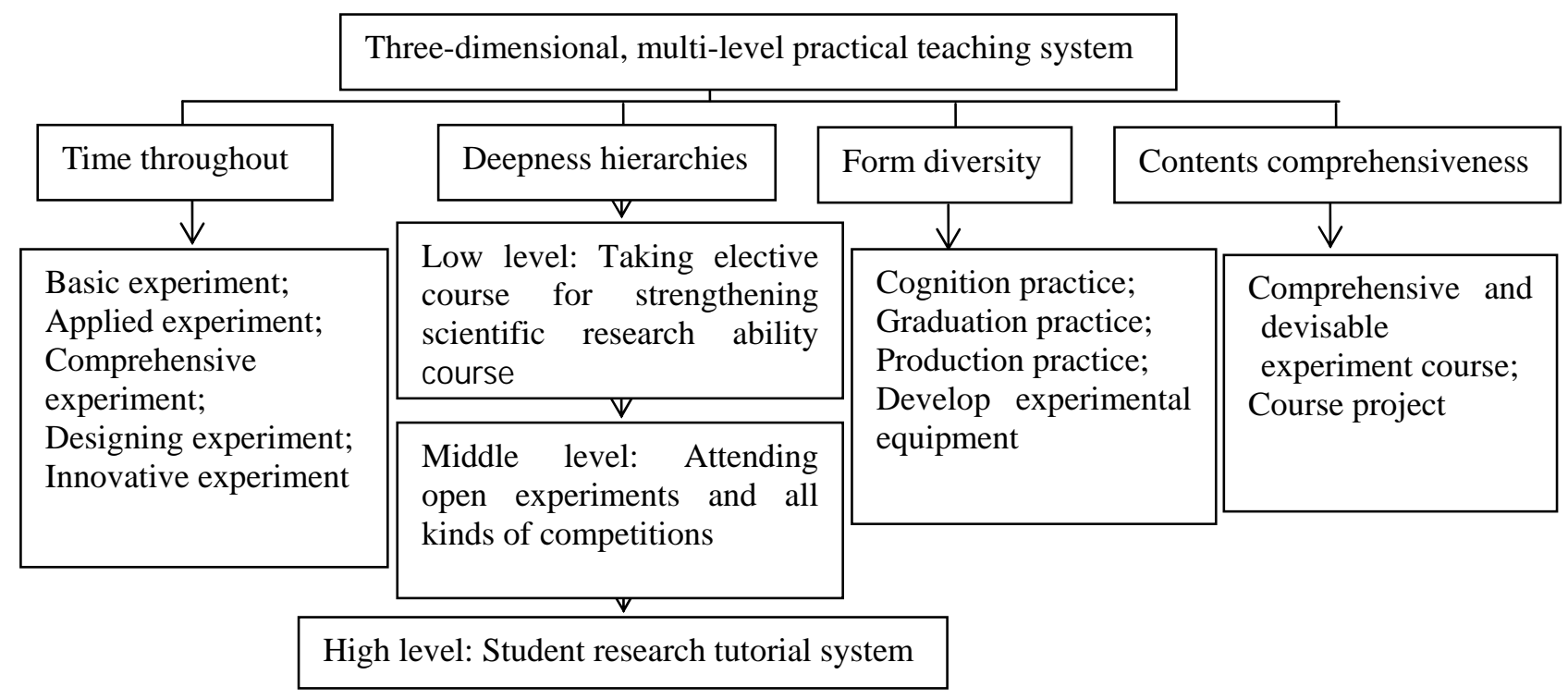

Fig.1. Multi-level three-dimensional practical teaching system

\section{Time Throughout of System}

The experimental teaching course system is running through from freshman year to senior year. The management modes of system is unified management, meticulous teaching for verification experiments; centralized management, guided teaching for comprehensive and designing experiments; opening management, heuristic teaching for innovative experiments in order to strengthen the cultivation of students' practical ability and innovative spirit.

The traditional experimental teaching is mainly based on the existing textbooks in which teaching materials are often behind the new knowledge and technologies. The experiments are mainly theoretical verification experiments which are obvious oneness and generally cramming education. Because teachers detailed explain experimental purposes, principles, contents and steps before the experiment, students needn't think and simply follow the expected conclusion on the mechanical operation of the established procedure, which greatly limits the student's personality development and innovative ability. The undergraduate experimental equipments tend to integration and systematization, which is very adverse for students' basic experimental quality development.

Reform of experimental teaching firstly proposed the idea of giving up equipments with high degree of integration, keeping equipments such as bread board, separate components and measurement equipments etc. And students are encouraged to independent develop laboratory equipment under the guidance of teachers.

While keeping the necessary validation experiments, to increase the proportion of comprehensive and designing experiments, and optimize the experimental structure, reflected the heritage and innovation of the experimental teaching reform. When training students' comprehensive ability to use discipline knowledge, mainly focus on the understanding of students' systems analysis, design, innovation, implementation, testing and debugging capabilities.

\section{Deepness Hierarchies of System}

Different types of students in different level will attend different practice teaching projects such as basic skills training, design capability training, comprehensive ability training, research ability training. There are three levels in practical system. The freshmen and sophomores could take elective courses for strengthening research capacity. Senior students could apply for innovative projects in open laboratory and participate in various competitions. The junior can attend the graduation projects. The high-level students can participate in the teachers' subjects for the further training of innovation ability and engineering practice ability [3].

Students are encouraged to participate in all kinds of practical skills competitions and research activities of teachers, further strengthening their sense of innovation and practice ability. In recent 
years, students have made remarkable achievements in many competitions such as National Aerospace Model Championship, Energy Conservation Game, "Challenge Cup" College Scientific and Technological Works, Undergraduate Electronic Design Contest. What is more important is that improving the practical ability and innovative ability become spontaneous demands for the majority of students. The teachers also actively create conditions to arrange more students into their own subjects. Because their innovation ability is greatly improved by participating in research activities, students appeared relatively strong competitive advantage in getting a job after college.

The open experiments stimulate students' consciousness and initiative because they could choose experimental content, make steps, choose equipment and analyze the experimental results and data all by themselves [4]. Our school has established Hebei Province production process automation engineering technology research center which provides very convenient conditions for students. The center is fully opened to enable students to verify their new ideas in the first time.

Graduation design is initial train of scientific research work for students to apply the basic theory, professional knowledge and basic skills. It is the important part of developing research capacity, practical ability and ability to work independently. Topics are all close engineering project. The design is not only stopped at the level of theoretical analysis, but also as far as possible hands-on design which effectively develop ability of comprehensive knowledge applied and innovation.

\section{Form Diversity of System}

The parts of cognition practice, graduation practice and production practice organically integrate the theories and practices. In order to help students understand the professional knowledge and application prospects, cognition practice is arranged before the third semester. After intuitive understanding specialized courses, students will enhance the study enthusiasm of their major.

Production practice takes the way of combination of school internship and off-campus internship. School internship demands students to complete the whole designing process which include material collection, design plan demonstration, component selection, hardware and software design, debugging, testing, report and other sectors within ten days, which is a significant challenge for senior students. Only cooperating closely can three students in one group hope to finish work in time, so the team spirit of cooperation will be strengthened. The practice in this way is very conducive to exercise their solving problem and practical performing ability [5]. Since 1995, our school has built cooperative relations with much internship for long-term scientific and technological education which provides strong support for innovative teaching. Students live in the factory, together work with the workers, completely practical train in industrial environment. Students' actual work ability and environmental adapt ability can be good exercised.

Graduation practice takes the way of combination of centralized internship and dispersed internship. According to students' own interests or intentions, students work in the internships which are related to the job orientation for six weeks. Students could get engineering experiences based on internships equipments and practical platform in order to realize the close docking with the social talents needs.

In the laddering practical teaching process of cognition practice, graduation practice and production practice, theoretical knowledge deepens step by step, and gradually develops the students' engineering thinking and engineering analysis capabilities.

\section{Contents Comprehensiveness of System}

Inherited in the form of theory courses plus experimental hours, designing experimental courses are offer independently. These courses such as 'AC and DC speed control system experiment' and 'process control system integrated experiment' have independent credits. Using open architecture the courses are related to process control technology, computer control technology, detection and conversion technology etc. Integrated variety of control methods such as PID control, fuzzy control, fuzzy PID control and Dalin algorithm, these experiments analyze the actual project according to practical engineering problems. Through the training of these experimental courses, students' 
handling ability and practical ability are trained. Whatever form of practical teaching, are all shifted from the traditional simplification to integration, in order to improve the effectiveness of the creative ability.

Practical courses usually set up a separate course. Students must complete system-level design for different topics in a week which include data query, system design, schematic drawing, specification writing, and finally reply. Reform for curriculum is mainly focusing on the following five aspects: wide range of design topics; independent thinking; require the application of advanced computer-aided software; reform evaluation criterion of scores; increase reply link.

\section{Conclusions}

After years of practice, under the premise of training engineering capabilities, a multi-level three-dimensional teaching practical system was built in this paper. All levels are accurate positioned and closely linked, integrated smooth transition with repeated intensive. The system focuses on students' normalization for basis experiment and systematicness; pays attention to the cultivation of innovative thinking and engineering quality. Practical results show that the practice teaching architecture is reasonable, and the effect is obvious, which effectively alleviate the contradiction between the student training and social needs, and resolve conflict between the quality and scale of college enrollment and resources. Our students are welcomed by employers, and employment rate is increased year by year due to the outstanding capacity of innovation.

\section{References}

[1] Zhou Jing, Chen Jia. The research and practice of engineering application ability training model for automation professionals. Science and Technology Innovation Herald, Vol. 9 (2008), p. 199

[2] Tang Guoxing. Innovation research and practice of practical teaching system of Mechanical engineering for applied undergraduate teaching. Mechanical Course Report Corpus (2008), p. 329

[3] Sun Xiaoyun, Zhang Gang, Du Yun, Liu Donghui. The research of innovative experimental areas construction for electrical and information innovative experimental areas. Journal of Electrical and Electronics Teaching, Vol. 1 (2010), p. 46

[4] Yang Zhou, Li Jing. The research of open experimental teaching for cultivating students' innovation ability. University Laboratory Work Research, Vol. 101 (2009), p. 32

[5] Wang Yong, Ye Dunfan. Students' innovative ability training based on college students' electronic design contest. Chinese Geological Education, Vol. 1 (2009), p. 145 